\title{
Pelatihan Penggunaan Aplikasi Rencana Pembelajaran PAUD di Kecamatan Bandung Wetan Kota Bandung
}

\author{
Enoh $^{1)}$, Huriah Rachmah ${ }^{2)}$, Masnipal $^{3)}$, Nurul Afrianti ${ }^{4)}$ \\ ${ }^{1)}$ Fakultas Tarbiyah dan Keguruan, Universitas Islam Bandung, enohnuroni@gmail.com, \\ ${ }^{2)}$ Fakultas Tarbiyah dan Keguruan, Universitas Islam Bandung, huriahrachmah@gmail.com \\ ${ }^{3)}$ Fakultas Tarbiyah dan Keguruan, Universitas Islam Bandung, masnipalmarhun@gmail.com \\ ${ }^{4)}$ Fakultas Tarbiyah dan Keguruan, Universitas Islam Bandung,nurulafrianti28@gmail.com
}

\begin{abstract}
ABSTRAK
Hasil pengamatan dan wawancara dengan guru, kepala sekolah serta Ketua HIMPAUDI Kecamatan Bandung Wetan Kota Bandung terungkap bahwa persoalan belum adanya aplikasi yang membantu kinerja guru dalam membuat rencana pembelajaran dan pelatihan tentang teknologi khususnya komputer menyebabkan guru-guru tidak memahami konten yang perlu dimasukkan ke dalam rencana pembelajaran dan cara memanfaatkan teknologi. Pengisian angket terhadap 10 guru PAUD menunjukkan data permasalahan terkait, diantaranya: (1) $90 \%$ guru belum membuat rencana pembelajaran secara rutin atau teratur, (2) $80 \%$ guru belum paham dalam membuat rencana pembelajaran, (3) $90 \%$ guru belum memanfaatkan teknologi komputer (manual) untuk mempermudah pembuatan rencana pembelajaran (4) $100 \%$ guru belum mempunyai aplikasi rencana pembelajaran berbasis komputer. Solusi yang diberikan antara lain: peningkatan kemampuan guru-guru PAUD dalam membuat rencana pembelajaran secara rutin atau teratur dengan menggunakan aplikasi pada setiap tahun ajaran agar guru selalu siap saat mengajar tidak terkendala dengan kegiatan pembelajaran yang akan diberikan kepada peserta didiknya serta pelatihan dalam menyusun rencana pembelajaran. Kegiatan pelatihan guru PAUD non formal ini dilaksanakan pada tanggal 18 Maret 2021 yang dihadiri oleh 16 orang guru PAUD di wilayah Kecamatan Bandung Wetan. Evaluasi pelatihan dilakukan melalui uji t-Paired. Dari hasil perhitungan didapat $p$-value sebesar 0.006 . Dengan derajat kepercayaan $95 \%$, karena $p$-value kurang dari 0,05, hal ini berarti terdapat perbedaan yang signifikan antara pengetahuan peserta sebelum dan sesudah pelatihan.
\end{abstract}

Kata-kata Kunci: Pelatihan, Rencana Pembelajaran, PAUD, Kecamatan Bandung Wetan

\begin{abstract}
The results of observations and interviews with teachers, school principals and the Head of HIMPAUDI, Bandung Wetan District, revealed that the problem of the absence of applications that help teacher performance in making lesson plans and training on technology, especially computers, causes teachers not to understand the content that needs to be included in lesson plans and how to use technology. Filling out a questionnaire to 10 Early Childhood Education teachers shows data on related problems, including: (1) $90 \%$ ofeachers have not made lesson plans routinely or regularly, (2) $80 \%$ of teachers do not understand in making lesson plans, (3) $90 \%$ of teachers have not utilized computer technology (manual) to facilitate the making of lesson plans (4) $100 \%$ of teachers do not yet have a computer-based learning plan application. The solutions provided include: increasing the ability of Early Childhood Education teachers in making lesson plans on a regular basis or regularly using applications every academic year so that teachers are always ready when teaching is not constrained by learning activities that will be given to their students as well as training in develop a lesson plan. This Non-formal Early Childhood Education teacher training activity was held on March 18, 2021, which was attended by 16 Early Childhood Education teachers in the Bandung Wetan District area. The evaluation of the training was carried out through the Paired t-test. From the calculation results obtained p-value of 0.006 . With a $95 \%$ confidence level, because the $p$-value is less than 0.05 , this means that there is a significant difference between the participants' knowledge before and after the training.
\end{abstract}

Keywords: Training, Lesson Plan; Early Childhood Education, District of Bandung Wetan 


\section{PENDAhULUAN}

Pendidikan Anak Usia Dini (PAUD) yang ideal adalah memiliki pendidik yang betulbetul mencintai anak sehingga tercipta hubungan kebatinan antara pendidik dan anak didik serta menghasilkan generasi penerus bangsa yang berkualitas (Christianti, 2015; Makarim, 2019). Oleh karena itu segala aspek yang mempengaruhi perkembangan dan pertumbuhan anak harus dirangsang secara maksimal termasuk berbagai bentuk pembelajaran yang diperlukan (Hijriati, 2017; Sriwahyuni \& Nofialdi, 2017; Tanu, 2019).

Pembelajaran PAUD yang baik tentunya memerlukan rencana pembelajaran yang menggunakan pendekatan dan model pembelajaran yang sesuai dengan kebutuhan, karakteristik anak dan budaya lokal serta meliputi program semester, rencana pelaksanaan pembelajaran mingguan (RPPM) dan rencana pelaksanaan pembelajaran harian (RPPH) yang disusun oleh pendidik pada program PAUD (Dewiastri \& Mulyana, 2020). Untuk menghasilkan generasi PAUD yang kreatif berdasarkan teori humanistik maka perlu peran guru yang kreatif dan mengikuti perkembangan teknologi dalam pemberian kegiatan pembelajarannya sehingga akan menghasilkan kegiatan yang holistik integratif. Teknologi informasi dan komunikas (ICT) dapat dimanfaatkan untuk meningkatkan kualitas dan produktivitas pendidikan (Nisa, 2020). Selain itu ICT dapat digunakan untuk keperluan pendidikan/pelatihan, komunikasi, administrasi, manajemen, media pembelajaran mandiri dan alat bantu pengajaran (Suharni et al., 2020).

Penggunaan teknologi dan informasi sebagai alat bantu pengajaran dapat menggunakan program Ms. Excel yang dimodifikasi sesuai dengan kebutuhan guru dalam merancang rencana pembelajaran, sehingga waktu akan lebih efisien dan beban kerja guru lebih ringan dan kemudahan dalam pembuatan rencana pembelajaran melalui aplikasi ini diharapkan dapat menambah pengetahuan tentang teknologi. Pelatihan penggunaan MS Excel dilakukan pada guru PAUD non-formal yang ada di wilayah Kecamatan Bandung Wetan.

Hasil pengamatan dan wawancara dengan guru, kepala sekolah serta Ketua HIMPAUDI Kecamatan Bandung Wetan terungkap bahwa persoalan belum adanya aplikasi yang membantu kinerja guru dalam membuat rencana pembelajaran dan pelatihan tentang teknologi khususnya komputer menyebabkan guru-guru tidak memahami konten yang perlu dimasukkan ke dalam rencana pembelajaran dan cara memanfaatkan teknologi. Pengisian angket terhadap 10 guru PAUD menunjukkan data permasalahan terkait, diantaranya: (1) $90 \%$ guru belum membuat rencana pembelajaran secara rutin atau teratur, (2) $80 \%$ guru belum paham dalam membuat rencana pembelajaran, (3) $90 \%$ guru belum memanfaatkan teknologi komputer (manual) untuk mempermudah pembuatan 
rencana pembelajaran (4) $100 \%$ guru belum mempunyai aplikasi rencana pembelajaran berbasis komputer.

Tujuan dari kegiatan pengabdian ini adalah untuk mengetahui kemampuan guru PAUD non formal dalam membuat perencanaan pembelajaran dan memberikan pelatihan tentang pembuatan perencanaan pembelajaran yang mudah. Manfaat yang diharapkan dari hasil penelitian ini adalah meningkatkanan kemampuan guru-guru PAUD dalam membuat rencana pembelajaran secara rutin atau teratur dengan menggunakan aplikasi pada setiap tahun ajaran agar guru selalu siap saat mengajar tidak terkendala dengan kegiatan pembelajaran yang akan diberikan kepada peserta didiknya.

\section{METODE PELAKSANAAN}

Pelaksanaan kegiatan pelatihan dilakukan oleh Program Studi Pendidikan Guru PAUD. Kegiatan dilaksanakan pada tanggal 18 Maret tahun 2021 dengan 2 sesi. Pada sesi pertama atau pembukaan, kegiatan pelatihan dibuka oleh Dekan Fakultas Tarbiyah dan Keguruan yaitu Enoh, Drs., M.Ag., kemudian dilanjutkan dengan pemberian lembar tes uji pre-test untuk mengukur pengetahuan awal seluruh mitra PKM. Pada sesi kedua acara dilanjutkan dengan materi pelatihan yang disampaikan oleh Enoh, Drs., M.Ag. dengan materi urgensi pengembangan program pembelajaran bagi AUD. Materi yang kedua disampaikan oleh Dr. Huriah Rachmah, M.Pd. dengan subyek materi yang berjudul Pelaksanaan Program Parenting pada Masa Belajar Dari Rumah (BDR). Materi ketiga dipaparkan oleh Dr. Masnipal, M.Pd. dengan judul materi Pembuatan RPPM dan RPPH pada Masa BDR. Materi pelatihan yang keempat dipaparkan oleh Nurul Afrianti, M.Pd., M.Si., Psi. Materi yang terakhir mengenai aplikasi pembelajaran dipaparkan oleh Putty Meuraxa, S.T., S.Pd.

Setelah materi selesai disampaikan maka seluruh peserta diberikan kembali tes pengetahuan tentang rencana pembelajaran. Tes ini dijadikan sebagai post-test yaitu untuk mengetahu sejauhmana pemahaman mitra setelah diberikan materi rencana pembelajaran oleh para pakar sebelumnya. Pada saat pelaksanaan, setiap mitra guru diajak bertukar fikiran tentang materi yang telah disampaikan maupun berbagai masalah yang dihadapi dalam membuat rencana pembelajaran dan proses pembelajarannya. Hal ini dilakukan sebagai bagian evaluasi bagi tim PKM dan guru untuk mengidentifikasi kemungkinankemungkinan masalah yang akan timbul. Apabila sudah teridentifikasi maka di dalam fokus pengembangan pembelajaran bagi anak akan lebih tepat sasaran karena sesuai dengan rencana pembelajaran yang sudah dibuatnya. Pada materi terakhir, mitra guru diminta dan diajak untuk praktek membuat rencana pembelajaran dengan aplikasi yang sudah diberikan. Foto peserta dan pelaksana kegiatan dapat dilihat pada Gambar 1. 


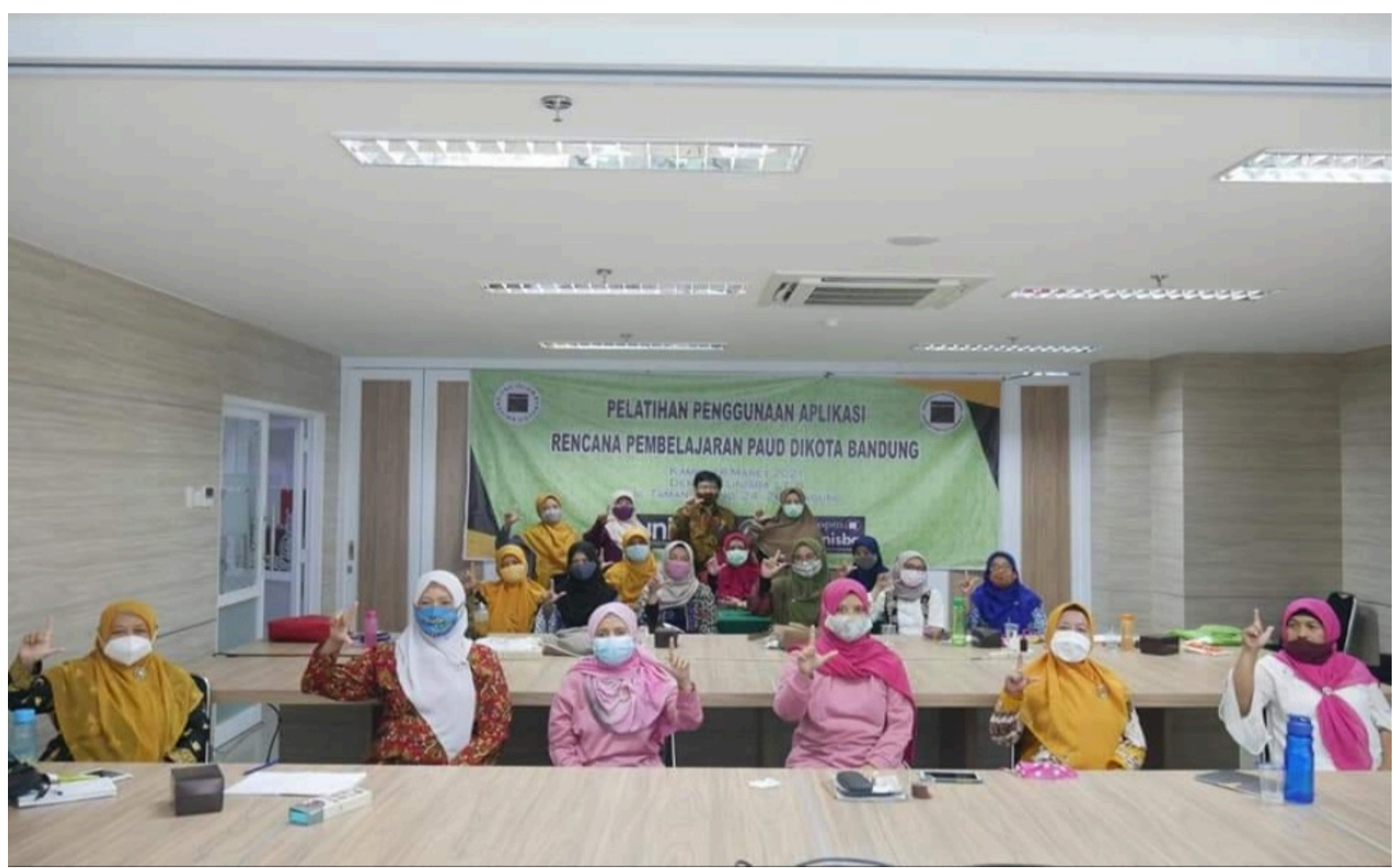

Gambar 1.

Kegiatan Pelatihan Penggunaan Aplikasi Rencana Pembelajaran PAUD

Setelah kegiatan selesai, mitra guru diajak curah pendapat terkait penyusunan rencana pembelajaran selama masa BDR. Hasilnya mitra guru banyak sekali menjawab belum secara maksimal membuat rencana pembelajaran selama masa BDR. Berdasarkan hasil diatas maka tim PKM menawarkan berbagai alternatif pengembangan program semester yang dapat dilakukan, diantaranya:

1. Pembuatan aplikasi rencana pembelajaran harian selama masa BDR. Guru di kelas mendapatkan kemudahan dalam membuat rencana pembelajaran menggunakan aplikasi.

2. Pembuatan aplikasi sesuai kebutuhan di setiap lembaganya

\section{HASIL DAN PEMBAHASAN}

Kegiatan pelatihan PKM bagi guru-guru di Kecamatan Bandung Wetan diikuti oleh 16 orang peserta yang berasal dari beberapa lembaga non formal di Kecamatan Bandung Wetan. Asesmen pengetahuan peserta uji coba terbatas sebelum pelatihan dilakukan melalui pre-test yang terdiri atas 10 pertanyaan. Setelah pelatihan dilakukan, peserta juga diminta mengerjakan post-test dengan pertanyaan yang sama untuk mengetahui apakah pengetahuan peserta bertambah. Nilai peserta sebelum dan sesudah pelatihan dapat dilihat pada Tabel 1, dengan nilai maksimum dari soal adalah 10. 
Tabel 1.

Nilai Pre-test dan Post-test Pelatihan

\begin{tabular}{|c|c|c|c|c|c|c|}
\hline No & Nama & $\begin{array}{c}\text { Usia } \\
\text { (Tahun) }\end{array}$ & Asal Sekolah & $\begin{array}{c}\text { Skor } \\
\text { Sebelum } \\
\text { Pelatihan }\end{array}$ & $\begin{array}{c}\text { Skor } \\
\text { Sesudah } \\
\text { pelatihan }\end{array}$ & Selisih \\
\hline 1 & ED & 43 & Paud Tresna sari & 6 & 7 & -1 \\
\hline 2 & CR & 53 & Paud Moeza & 3 & 4 & -1 \\
\hline 3 & TW & 35 & KB Karangsari & 6 & 6 & 0 \\
\hline 4 & Kur & 46 & KB Al Barokah & 4 & 7 & -3 \\
\hline 5 & AN & 24 & Paud Penentram Hati & 8 & 9 & -1 \\
\hline 6 & YH & 37 & KB Mutiara Ibu & 5 & 7 & -2 \\
\hline 7 & SN & 25 & Paud An Nur & 2 & 6 & -4 \\
\hline 8 & TS & 49 & KB Mitra Tanaya & 6 & 7 & -1 \\
\hline 9 & LH & 43 & SPS Al Latif & 4 & 3 & 1 \\
\hline 10 & RP & 49 & Paud Anggrek & 8 & 8 & 0 \\
\hline 11 & HH & 28 & KB Az-Zahra & 6 & 6 & 0 \\
\hline 12 & Ju & 48 & KB Az-Zahra & 6 & 9 & -3 \\
\hline 13 & EL & 47 & KB Karangsari & 6 & 7 & -1 \\
\hline 14 & DH & 39 & KB Mutiara Ibu & 7 & 7 & 0 \\
\hline 15 & AH & 31 & KB Mutiara Ibu & 9 & 10 & -1 \\
\hline 16 & EM & 56 & KB Karangsari & 5 & 5 & 0 \\
\hline
\end{tabular}

Tabel 1 menunjukkan bahwa mayoritas peserta pelatihan mengalami peningkatan nilai setelah pelatihan meskipun masih ada beberapa peserta yang tidak mengalami peninngkatan bahkan sedikit menurun. Namun, untuk memastikan, akan diperiksa perbedaan skor tersebut menggunakan Uji t-paired. Pertama-tama, selisih nilai pre-test dan post-test diuji kenormalannya menggunakan Uji Kolmogorov-Smirnov. Karena nilai signifikan $>0,05(0,118>0,05)$ maka residual atau data selisih nilai pretest dan posttest berdistribusi normal. Karena data berdistribusi normal, data selanjutnya diuji menggunakan Uji t-paired. Uji ini dilakukan menggunakan software statistika. Dari hasil perhitungan didapat $p$-value sebesar 0,006 . Dengan derajat kepercayaan $95 \%$, karena $p$-value kurang dari 0,05 , hal ini berarti terdapat perbedaan yang signifikan antara pengetahuan peserta sebelum dan sesudah pelatihan.

Hasil pelatihan perencanaan pengajaran menunjukkan terjadinya peningkatan kemampuan guru PAUD dalam membuat rencana pembelajaran. Hal ini sesuai dengan hasil pelatihan yang dilakukan oleh Pramudyani dan Rohmadheny yang menunjukkan peserta memiliki rasa ingin tahu dan antusiasme yang tinggi untuk mempelajari dan mempraktekkan penggunaan MS-Office selama proses pelatihan (Pramudyani \& Rohmadheny, 2019). Pelatihan lain menunjukkan kemampuan guru TK dalam membuat RPPM dan RPPH meningkat dengan melihat hasil kerja guru TK menggunakan Aplikasi 
Penyusunan Perencanaan Pembelajaran (AP3) serta waktu yang dibutuhkan untuk menyelesaikan penyusunan RPPM dan RPPH lebih singkat (Rohita et al., 2018).

\section{KESIMPULAN}

Kegiatan ini menghasilkan kesimpulan bahwa salah satu masalah yang dikemukakan oleh guru PAUD adalah membuat perencanaan pembelajaran. Pelaksanaan pengabdian dilaksanakan menjadi dua bagian yaitu pelaksanaan pertama fokus kepada pelatihan, dan kedua yaitu evaluasi capaian dari hasil pelatihan. Selanjutnya tim menetapkan sasaran pelatihan, yakni dibatasi hanya sejumlah 16 orang guru dan kepala sekolah dari 11 PAUD non formal yang ada disekitar Kecamatan Bandung Wetan, Kota Bandung. Materi pelatihan yang diberikan antara lain: urgensi pengembangan program pembelajaran bagi AUD, pelaksanaan program parenting pada masa BDR, pembuatan RPPM dan RPPH masa BDR, kegiatan pembelajaran masa BDR bagi ABK, aplikasi pembelajaran. Hasil uji t-paired menunjukkan bahwa terdapat perbedaan yang signifikan pada pengetahuan peserta antara sebelum pelatihan dan setelah mengikuti pelatihan. Oleh karena itu dapat disimpulkan bahwa kegiatan pelatihan ini memberikan dampak positif bagi para peserta.

\section{REFERENSI}

Christianti, M. 2015. Profesionalisme Pendidik Anak Usia Dini. Jurnal Pendidikan Anak, 1(1). https://doi.org/10.21831/jpa.v1i1.2923

Dewiastri, A. R., \& Mulyana, E. H. 2020. Keterampilan Mengomunikasikan Anak Usia Dini. Jurnal PAUD Agapedia, 4(1), 50-70.

Hijriati. 2017. Pengembangan Model Pembelajaran Pendidikan Anak Usia Dini. Januari Juni, 1, 74-92.

Makarim, N. 2019. PAUD yang Ideal Menurut Mas Menteri. GTK PAUD Kemdikbud. Diunduh dari: https://gtk.kemdikbud.go.id/read-news/paud-yang-ideal-menurut-masmenteri

Nisa, L. 2020. Pemanfaatan Teknologi Dalam Pendidikan Anak Usia Dini. ThufuLA: Jurnal Inovasi Pendidikan Guru Raudhatul Athfal, 8(1), 001. Diunduh dari: https://doi.org/10.21043/thufula.v8i1.6283

Pramudyani, A. V. R. \&, \& Rohmadheny, P. S. 2019. Pelatihan pemanfaatan aplikasi microsoft office dalam pembelajaran sebagai upaya peningkatan profesionalisme bagi guru PAUD di PCA Mantrijeron. Seminar Nasional Hasil Pengabdian Kepada Masyarakat Universitas Ahmad Dahlan, September, 711-718. Diunduh dari: http://seminar.uad.ac.id/index.php/senimas/article/view/2312/612

Rohita, R., Fitria, N., \& Haryadi, D. 2018. Pemanfaatan Aplikasi Penyusunan Perencanaan Pembelajaran (Ap3) Dalam Penyusunan Perencanaan Pembelajaran Bagi Guru Taman Kanak-Kanak Di Jakarta. Jurnal Pengabdian Kepada Masyarakat, 24(2), 644. Diunduh dari: https://doi.org/10.24114/jpkm.v24i2.10168 
Sriwahyuni, E., \& Nofialdi, N. 2017. Metode Pembelajaran Yang Digunakan Paud (Pendidikan Anak Usia Dini) Permata Bunda. ThufuLA: Jurnal Inovasi Pendidikan Guru Raudhatul Athfal, 4(1), 44-62. Diunduh dari: https://doi.org/10.21043/thufula.v4i1.2010

Suharni, Wahyuni, \& Salmah, S. 2020. Pengelolaan Kelas Pada Model Pembelajaran Kelompok Pada Anak Usia 5-6 Tahun Di TK IT Al- Mahira, PAUD Lectura: Jurnal Pendidikan Anak Usia Dini, 3(2), 68-77.

Tanu, I. K. 2019. Penggunaan Metode Mengajar Di Paud Dalam Rangka Menumbuhkan Minat Belajar Anak. Pratama Widya : Jurnal Pendidikan Anak Usia Dini, 3(2), 14-19. Diunduh dari: https://doi.org/10.25078/pw.v3i2.733 